\title{
Bilateral lower limb edema induced by rapid improvement of glycemic control with insulin therapy in a subject with poorly controlled type 2 diabetes
}

\author{
Yuki Kan $^{1} \cdot$ Takatoshi Anno $^{1}$ (D) Fumiko Kawasaki $^{1} \cdot$ Maiko Takai $^{1} \cdot$ \\ Ryo Shigemoto $^{1} \cdot$ Hideaki Kaneto $^{2} \cdot$ Kohei Kaku $^{1} \cdot$ Niro Okimoto $^{1}$
}

Received: 27 March 2017/ Accepted: 19 April 2017/Published online: 27 April 2017

(c) The Author(s) 2017. This article is an open access publication

\section{Dear Editor,}

A 57-year-old man who had 5-year history of type 2 diabetes (T2DM) but hesitated to receive its treatment was referred to our department. His height and body weight were $164.0 \mathrm{~cm}$ and $48.0 \mathrm{~kg}$. His vital signs were: heart rate 75 beats/min, blood pressure $122 / 65 \mathrm{mmHg}$, and temperature $36.9{ }^{\circ} \mathrm{C}$. Non-fasting plasma glucose was markedly elevated to $579 \mathrm{mg} / \mathrm{dL}$. HbA1c and glycoalbumin levels were also markedly elevated to 19.4 and $110.1 \%$. Serum insulin level was as low as $<1.0 \mu \mathrm{U} / \mathrm{mL}$. $\beta$-Hydroxybutyrate and acetoacetate were 267.9 and $172.6 \mu \mathrm{mol} / \mathrm{L}$. Anti-GAD antibody was negative. Renal and liver function was within normal range. Brain natriuretic peptide (BNP) was $63.5 \mathrm{pg} / \mathrm{mL}$. Urinary albumin excretion was $234 \mathrm{mg} / \mathrm{g}$ creatinine, and urine protein $(3+)$ was detected in urinalysis.

His life style was very poor; for example, he drunk 1-2 L of PET bottle of juice and ate a lot of snacks and fruits. At first, we treated him with diet therapy of $1600 \mathrm{kcal} /$ day (about $28 \mathrm{kcal} /$ ideal body weight $\mathrm{kg}$ ) and sodium restriction of $6 \mathrm{~g} /$ day. In addition, we started basal insulin (4 units of degludec) once a day and bolus insulin (4 units of aspart) before each meal. He was followed up as an outpatient, and we increased insulin dose gradually each

Managed by Antonio Secchi.

Takatoshi Anno

anno-t@umin.ac.jp

1 Department of General Internal Medicine 1, Kawasaki Medical School, 2-6-1 Nakasange, Kita-ku, Okayama 700-8505, Japan

2 Department of Diabetes, Metabolism and Endocrinology, Kawasaki Medical School, Kurashiki 701-0192, Japan
1 week. And we treated him with 6 units of degludec and 22 units of aspart $(8,6$, and 8 units before breakfast, lunch, and dinner) for 2 weeks. HbA1c and glycoalbumin levels were very rapidly decreased only in 3 weeks from 19.4 to $14.5 \%$ and from 110.1 to $69.5 \%$, respectively (Fig. 1a). After starting insulin therapy, overt pitting edema was observed in both legs (Fig. 1b). Lower limb ultrasound clearly revealed the fluid accumulation under subcutaneous fat in the bilateral lower limbs (Fig. 1c). In addition, his body weight was increased by $7 \mathrm{~kg}$ only for 2 weeks. In an echocardiogram, his heart movement was normal and ejection fraction (EF) was $62.1 \%$, although BNP level was increased to $192.1 \mathrm{pg} / \mathrm{mL}$. Renal and liver function was within normal range. TSH and FT4 levels were $2.726 \mu \mathrm{IU} /$ $\mathrm{mL}$ and $0.73 \mathrm{ng} / \mathrm{dL}$. Urine protein $(2+)$ was detected in urinalysis. Even after starting treatment with $4 \mathrm{mg} /$ day of torasemide, his leg edema was not reduced. Since his glycemic control was improved, we reduced insulin to 4 units of degludec and 16 units of aspart. Without changing to another kind of insulin, his bilateral lower limb edema was markedly improved and BNP level was decreased to $60.8 \mathrm{pg} / \mathrm{mL}$.

It is known that insulin therapy increases the reabsorption of sodium at the level of the renal tubule which leads to the development of insulin edema. In addition, it is known that insulin treatment leads to hyperaldosteronism which could be also involved in the development of insulin edema. There were a few reports about insulin edema all of which were reduced after changing to another kind of insulin [1-4]. In this case, however, bilateral lower limb edema was markedly improved without changing to another kind of insulin. Therefore, we think that bilateral lower limb edema in this subject was induced by the rapid improvement of glycemic control rather than the introduction of insulin therapy per se. There are several possible 


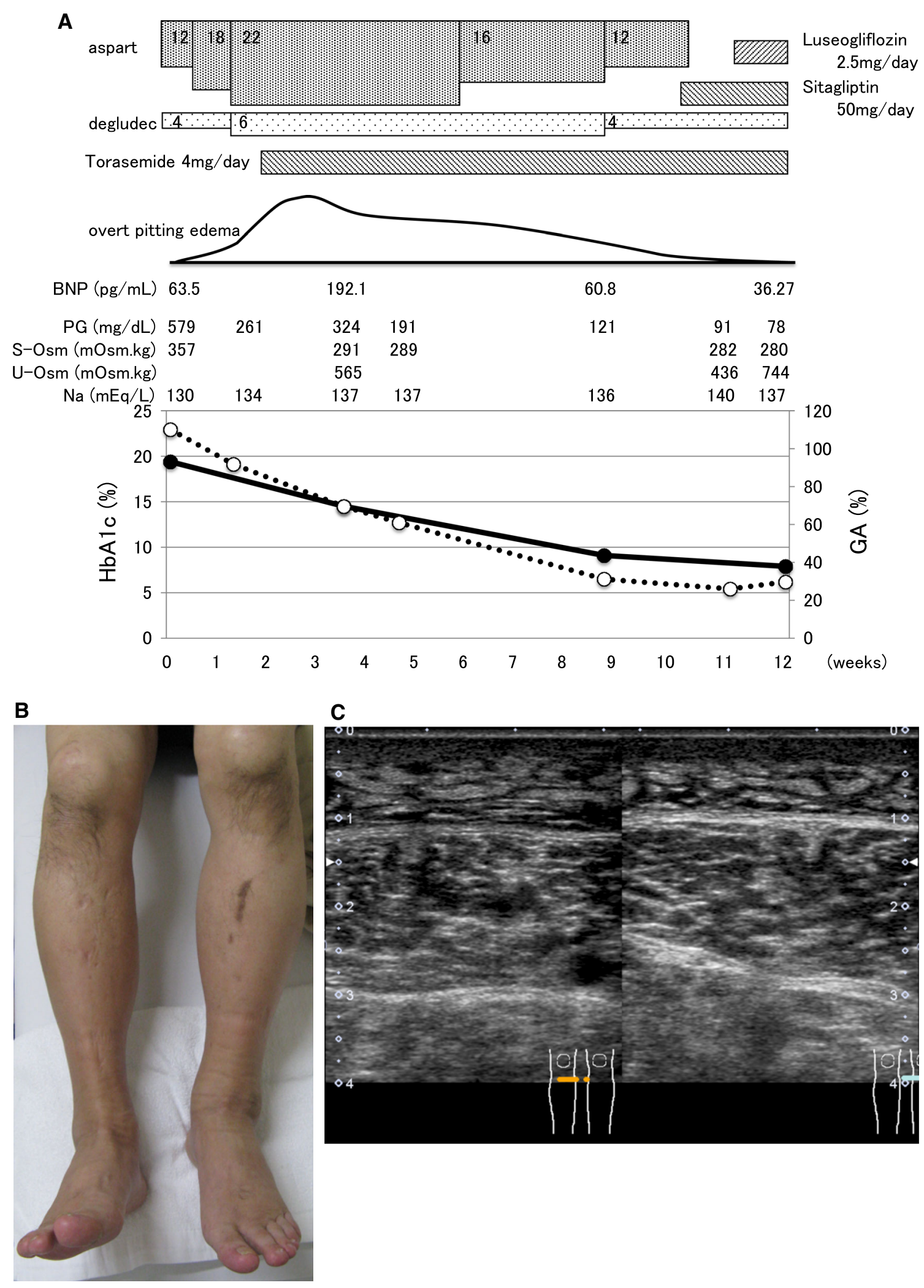

Fig. 1 a Time course of various clinical parameters in this subject. b Bilateral edema in ankles and pretibial region. c Lower limb ultrasound revealing fluid accumulation under subcutaneous fat in the bilateral lower limbs 
mechanisms for the development of edema induced by rapid improvement of glycemic control. For example, it is possible that rapid improvement of glycemic control reduces plasma osmolality which leads to intracellular water retention and brings out edema. Indeed, plasma osmolality in this subject was decreased after the improvement of glycemic control (Fig. 1a). It remains unknown, however, why such rare phenomena were observed in this subject. In addition, it is possible that the difference in salt sensitivity is, at least in part, involved in the development of such phenomena, but it remains unknown whether such phenomena are relatively easily induced in Japanese subjects whose salt sensitivity is thought to be different from those in Caucasians. In order to address this point, it would be necessary to perform future clinical study with large population. Taken together, we assume that the edema in this subject was induced by the alteration of various parameters after rapid improvement of glycemic control such as plasma osmolality rather than by the introduction of insulin therapy per se.

In conclusion, we should keep in mind the possibility that when we try to obtain good glycemic control with insulin therapy especially in subjects with poorly controlled diabetes, edema is induced not only by the introduction of insulin therapy per se but also by the alteration of various parameters after rapid improvement of glycemic control such as the alteration of plasma osmolality.

\section{Compliance with ethical standards}

Conflict of interest The authors declare that they have no conflict of interest.
Human and animal rights All procedures followed were in accordance with the ethical standards of the responsible committee on human experimentation (institutional and national) and with the Helsinki Declaration of 1975, as revised in 2008.

Informed consent Informed consent was obtained from the patient for being included in the study.

Open Access This article is distributed under the terms of the Creative Commons Attribution 4.0 International License (http://crea tivecommons.org/licenses/by/4.0/), which permits unrestricted use, distribution, and reproduction in any medium, provided you give appropriate credit to the original author(s) and the source, provide a link to the Creative Commons license, and indicate if changes were made.

\section{References}

1. Kawashima S, Kaneto H, Sakamoto K, Yasuda T, Kuroda A, Shiraiwa $\mathrm{T}$ et al (2008) Acute progression of severe insulin edema accompanied by pericardial and pleural effusion in a patient with type 2 diabetes. Diabetes Res Clin Pract 81(2):e18-e19

2. Kuroe A, Taniuguchi A, Fukushima M, Nakai Y, Ohgushi M, Ohya $\mathrm{M}$ et al (2007) Early and late onset side effects of shortacting insulin analogue in seven Japanese diabetic patients. Diabetes Res Clin Pract 77(3):412-413

3. Tone A, Shikata K, Nakagawa K, Hashimoto M, Makino H (2008) A case of hypoglycemic brittle diabetes with peripheral edema successfully managed by conversion from insulin lispro to insulin aspart. Diabetes Res Clin Pract 81(3):e15-e16

4. Succurro E, Ruffo M, De Sarro G, Gallelli L, Arturi F (2015) Bilateral lower limbs edema with "wooden" character induced by insulin glargine treatment. Acta Diabetol 52(4):809-811 